\title{
O lugar das organizações internacionais no sistema internacional: ideias, governança e transnacionalismo
}

The place of international organizations in the international system: ideas, governance and transnationalism

José Maria de Souza Júnior ${ }^{1}$

\section{Resumo}

O presente artigo junta as discussões sobre ideias em política, governança global e transnacionalismo para saber o lugar das OIGs no sistema internacional. Elas são: 1) palco de contato entre Estados e para pressão de atores não estatais; 2) origem de produção de conhecimento e dados utilizados por diversos atores para o desenho de políticas, pesquisas e posicionamentos; 3) arenas de "fricção" entre Estados fortes e posições contra majoritárias de outros atores; 4) chance de representação de Estados fracos e emergentes; 5) atores decisivos no contexto de "sociedade global".

Palavras-chave: organizações internacionais; ideias; governança; transnacionalismo.

\section{Abstract}

This article puts together the literature about the influence of ideas in politics, global governance and transnationalism to know the place the IO's have in international relations. They are: 1) contact arena among states and pressure for non-state actors; 2) origin of knowledge production and data used by many different actors for policy design, reserach and positioning; 3)"friction" arena between strong states and counter-majoritary positions from other actors; 5) decisive actors in the "global society" context.

Key-words: International Organizations; Ideas; Governance; Transnationalism.

\section{Introdução}

Este ensaio tem como objetivo elucidar o lugar das organizações internacionais interestatais no sistema internacional, como atores políticos, utilizando três eixos teóricos da literatura de Relações Internacionais: 1) a perspectiva ideacional em política, traduzindo a importância das ideias nas ações e formulações políticas em geral; 2) a ideia

\footnotetext{
1 Professor de Relações Internacionais das Faculdades Rio Branco em São Paulo. Mestre pelo Programa de Pós-Graduação em Integração da América Latina (USP) e doutorando no Departamento de Ciência Política da Universidade de São Paulo. São Paulo, Brasil.
} 
de governança global como práticas exercidas por um sistema humano de acordo com suas demandas; e 3) a noção de transnacionalismo tendo por base o caráter assumido pela sociedade global no qual as fronteiras se encontram cada vez mais vulneráveis em relação aos movimentos que as transcendem. Assim, é pertinente questionar-se sobre qual é o papel ou os papéis que as OIGs desempenham nesse contexto.

Assim, são cinco as conjecturas consideradas neste estudo em relação ao referido papel das OIGs: 1) são um importante palco de contato e negociação entre Estados e com cada vez mais espaço para a pressão de atores não estatais; 2) são origem de produção de conhecimento e de dados utilizados por diversos atores para o desenho de políticas, pesquisas e posicionamentos políticos; 3) são arenas de "fricção" entre Estados (principalmente os fortes) e posições contramajoritárias de outros atores; 4) são chance de representação de Estados mais fracos e emergentes; 5) são atores decisivos no contexto de "sociedade global", uma vez que possuem atuação em diversos temas, ganhando relevância, assim como uma série de atores privados. Reconhece-se que esses elementos possuem grau de intersecção entre eles. Contudo, advoga-se que, mesmo assim, cada um possui um núcleo específico e independente dos outros.

Basicamente, o presente estudo advoga que as organizações internacionais são entidades políticas indispensáveis para o modelo de relações que o mundo apresenta hoje, embora estas não sejam as entidades centrais. Trata-se, portanto, de um ensaio teórico que faz uma revisão de literatura sobre a questão das ideias em política, governança global e transnacionalismo e, a partir da reflexão conceitual acerca desses três temas, o trabalho tece conjecturas também teóricas sobre o lugar da OIGs no sistema internacional. Em virtude de limitações de espaço e escopo, este trabalho não possui a ambição de provar tais conjecturas empiricamente.

Assim, a primeira parte do trabalho se debruça sobre a temática das ideias e como estas influenciam a política, dando ênfase à dimensão de que as OIGs são resultado de uma posição ideacional de política e também, hoje em dia, fornecem ideias para tal política. Posteriormente, trata-se da governança global e do transnacionalismo e de como os dois elementos estão interligados, ou seja, a governança é criada pela ação de movimentos transnacionais e de outros atores, entre eles as OIGs. A seção seguinte tece, do ponto de vista teórico, as cinco conjecturas já apresentadas sobre o papel das organizações internacionais no sistema internacional. Por fim, as considerações finais apontam 
possíveis caminhos a serem percorridos em estudos futuros, tanto empíricos como teóricos, para a melhor compreensão do fenômeno tratado.

\section{Ideias e política}

Para ter base formativa sobre como encontrar o lugar das OIGs no sistema internacional, o trabalho considera a noção do papel das ideias em política. Ideias possuem implicações nas ações humanas e, por consequência, nas relações internacionais. Goldstein e Keohane (1993) trabalham com o impacto de crenças sobre a natureza do mundo que são divididas por um grande número de pessoas e que têm implicações nas ações humanas.

Para esses autores, "ideias podem tornar-se importantes até mesmo por conta do interesse e do poder de seus progenitores" (GOLDSTEIN; KEOHANE, 1993, p. 13, tradução nossa). Contudo, eles refutam a premissa de que os atores agem somente de acordo com seus interesses: tanto interesses quanto ideias e crenças possuem relevância nas ações humanas, pois ideias ajudam a esclarecer princípios e concepções de relações causais e coordenam ações de indivíduos.

Com efeito, duas perguntas são pertinentes: 1) em quais circunstâncias as ideias são relevantes na política?; e 2) quando se pode sentir o efeito de mudanças em ideias?. Em relação à primeira pergunta, os autores afirmam que ideias são eficazes do ponto de vista da política se forem acompanhadas por outras mudanças, como, por exemplo, mudanças em interesse material ou relação de poder. Já para responder à segunda pergunta, eles afirmam que as mudanças nas ideias passam a ser sentidas depois que o consenso político de uma issue area fica desestabilizado (GOLDSTEIN; KEOHANE, 1993, p. 26).

Das ideias derivam as crenças. Goldstein e Keohane (1993, p. 7-11) fizeram a distinção entre três tipos de crenças: 1) world views (visões de mundo), a forma na qual as ideias possuem impacto mais significativo; 2) principled beliefs (o termo pode ser traduzido como crenças baseadas em princípios), que são ideias de cunho normativo e servem para distinguir certo e errado, justo e injusto2; e 3) causal beliefs (crenças causais), que são crenças sobre relações de causa e efeito as quais providenciam guias para

\footnotetext{
${ }^{2}$ As crenças baseadas em princípios são frequentemente arraigadas em certas visões de mundo, mas essas visões de mundo podem ser suficientemente extensas a ponto de fornecerem bases simultaneamente a crenças baseadas em princípios que sejam opostos uns aos outros (GOLDSTEIN; KEOHANE, 1993, p. 9).
} 
indivíduos com relação à maneira pela qual estes podem atingir seus objetivos ${ }^{3}$. Dessa forma, é preciso fazer a distinção entre ideias que servem como valores (principled beliefs) e ideias que servem como métodos ou guias para atingir certos objetivos (causal beliefs).

Pode-se concluir que essas três perspectivas estão ligadas e promovem mudanças em políticas com intensidades diferentes. As duas primeiras são as que promovem mudanças mais profundas e acontecem de forma menos frequente, ao passo que as mudanças em causal beliefs são mais comuns e acontecem mais frequentemente. É, contudo, um erro assumir conexão causal entre ideias e crenças dos tomadores de decisão e escolhas políticas, pois tais crenças podem simplesmente significar interesses de certos atores. Assim, o cientista dedicado ao estudo de ideias deve identificar as ideias descritas e os resultados de política (policy outcomes) ou mudanças institucionais que devem ser explicados; deve também fornecer evidências das condições sob as quais conexões causais existem entre ideias e policy outcomes. Nesse sentido, pode-se estabelecer uma relação inicial entre as visões de mundo e as crenças baseadas em princípios em relação às organizações interestatais: após a Segunda Guerra Mundial, esse tipo de organização passa a fazer parte do modus operandi da política internacional, ou seja, a forma como se passou a fazer política depois das duas grandes guerras foi através das OIGs, mesmo estas não sendo o principal ator das relações internacionais.

Goldstein e Keohane afirmam que "ideias ajudam a ordenar o mundo. Ordenando o mundo, ideias formam agendas que podem ter impacto profundo na formação de resultados (outcomes)" (GOLDSTEIN; KEOHANE, 1993, p. 12, tradução nossa). Para eles, as ideias afetam a política de três formas:

1) fornecendo road maps: essa forma não significa a eleição de uma ideia que implique uma escolha específica de ação, mas, quando se tem uma ideia selecionada, os road maps acabam por limitar escolhas, pois aquela ideia automaticamente exclui a possibilidade de trabalhar com outras que forneceriam diferentes alternativas;

2) afetando estratégias que não possuem apenas um ponto de equilíbrio (estratégias de equilíbrio variável), ou seja, onde os atores buscam estratégias de interações que tenham resultados mais eficientes, sendo que tais resultados garantam, ao

\footnotetext{
${ }^{3}$ Essas crenças são incorporadas em instituições (em virtude de serem regras de conduta) e seus resultados dependem da ação coordenada de grupos de indivíduos. Assim, as causal beliefs dependem de uma gama de principled beliefs que sejam comuns entre grupos, e estes, por sua vez, podem ser compreendidos em um contexto mais amplo de world views.
} 
menos, o status quo para todos os participantes. Assim, ideias servem como focal points que definem soluções cooperativas e coesão entre grupos. 0 argumento aqui é que as ideias e crenças dos jogadores (em uma negociação, por exemplo) são cruciais para a compreensão dos resultados quando os "jogos" (rodadas de negociações) são repetidos várias vezes, pois esses jogos possuem múltiplos pontos de equilíbrio. Em outras palavras, saber as ideias e crenças dos atores aumenta o poder de previsão dos resultados quando jogos/rodadas de negociações são repetidos; e

3) permeando instituições, ou seja, quando ideias estão no formato de regras e normas. "Ideias que estão incorporadas em instituições especificam as políticas na ausência de inovação" (GOLDSTEIN; KEOHANE, 1993, p. 13, tradução nossa). Assim, quando uma escolha política leva à construção de estruturas normativas e organizacionais, a ideia que deu origem à escolha política pode afetar os incentivos dos empreendedores políticos muito depois que os interesses dos propositores iniciais (da ideia) já tiverem mudado.

The existence of international institutions give states great incentives to make their policies more consistent with one another and with prevailing norms, so that they can be more successfully defended in international forums... and changes in prevailing ideas - world views, principled beliefs or causal beliefs - typically become institutionalized at some point (GOLDSTEIN; KEOHANE, 1993, p. 24-25).

Com efeito, é perceptível que o amplo número de OIGs atuantes hoje na política internacional declara que esse tipo de organização cumpre as funções derivadas de ideias e crenças que fazem parte da forma como a política é exercida. 0 que está em jogo aqui não é se as OIGs funcionam mais ou menos em termos de atingir objetivos determinados, mas, sim, dizer que elas fazem parte do jogo político e da determinação dos interesses nas relações internacionais e, por isso, são alvo de estudo no campo das Relações Internacionais. Além disso, Krasner (apud GOLDSTEIN; KEOHANE, 1993, p. 22) mostra que um dos papéis das ideias é codificar práticas que já estão em curso em vez de iniciar novas formas de ordenamento. Dessa forma, pode-se entender que as práticas ou mudanças de conduta acontecem a priori à elaboração conceitual de novas ideias. A construção intelectual para descrever e explicar tais práticas acontece depois que elas já estão em curso.

O impacto de ideias é grande e extrapola os objetivos pelos quais tais ideias foram implantadas. Os autores dão o exemplo de que as ideias sobre direitos humanos não objetivavam o movimento em favor da liberdade das colônias (na África) nem a proteção 
de pessoas dentro de Estados nacionais, mas, mesmo assim, tais ideias tiveram esses efeitos e provocaram o esgotamento do colonialismo a partir dos anos 1950 (GOLDSTEIN; KEOHANE, 1993, p. 25).

A abordagem formulada por Hall (1989) e Jenson (1989) propõe o conceito de paradigma de políticas públicas. De acordo com esses autores, um paradigma de política pública é um construto intelectual ligado a uma área de políticas (policy subsystem), que contém o conjunto de ideias e percepções que são compartilhadas pelos atores políticos relevantes para a área. Esse construto intelectual consiste num conjunto interligado de percepções, atitudes, ideias e valores que permitem a "correta" identificação e definição do problema-alvo da política, as características estratégicas dos seus instrumentos e os seus resultados esperados. As ideias podem ter um grau considerável de independência sobre as circunstâncias; contudo, a influência de um conjunto de novas ideias não depende somente da qualidade das ideias em questão (HALL, 1989, p. 369). Dessa forma, Hall considera três elementos circunstanciais externos que podem afetar a influência de novas ideias em dada política: 1) para serem adotadas, as ideias dependem do modo como elas se relacionam com os problemas econômicos, políticos (e específicos da área em que elas são formuladas), ou seja, deve haver congruência entre ideias e circunstâncias; 2) a interpretação das ideias pode ser diferente dependendo da experiência histórica local; 3) é necessário que haja o endosso da autoridade local e o contato com os formuladores e tomadores de decisão. Nesse aspecto, a organização da tomada de decisão afeta o fluxo de informações e o acesso dos tomadores. Assim, torna-se pertinente saber a quais ideias eles têm acesso e quais autoridades são consultadas. Dessa forma, conclui-se que a disseminação e a implementação de ideias devem ser alvos de explicação mais do que as ideias em si (HALL, 1989, p. 370). Assim, as ideias devem atingir níveis satisfatórios de viabilidade econômica, política e administrativa para ser implementadas. Olhando para as abordagens de Hall (1989) e Goldstein e Keohane (1993), observa-se que ideias, interesses e as circunstâncias em que acontecem as relações sociais são importantes quando se trata de mudança em Ciência Política. Ideias sozinhas não fornecem toda a base para a implementação de políticas públicas, pois interesses são tão ou mais importantes que as próprias ideias. Não obstante, tais ideias não estão dissociadas dos interesses.

As ideias dão a base e/ou justificam as ações políticas à medida que moldam as visões de mundo e as crenças sobre variados temas participantes da vida política. 
Somadas ao contexto político, econômico e social, ideias ensejam novas discussões e debates nas sociedades, fazendo com que as práticas e, consequentemente, as políticas para diferentes áreas mudem com o passar do tempo.

Assim, as ideias são importantes para a vida política em geral, tanto doméstica quanto internacional. Em outras palavras, as ideias influenciam tanto Estados (na verdade, trata-se da influência exercida sobre os tomadores de decisão dos Estados) quanto organizações internacionais. Nesse sentido, as OIGs fazem parte da lógica de criação de políticas através das ideias, de forma que o modo de se fazer política no sistema internacional após a Segunda Guerra Mundial incorporou esse tipo de organização.

\section{Governança global}

Para iniciar o debate proposto nesta seção do artigo, há dois passos a serem dados. 0 primeiro trata de discutir o termo governança e, posteriormente, tratará da governança global. Governança ou "boa governança” são termos defendidos publicamente por políticos e politólogos como sendo moralmente desejados e, nesse sentido, algo a ser buscado. Obviamente, o presente artigo buscará tratar da definição teórica dentro da profundidade possível para este termo e debaterá qual tipo de governança pode ser praticado e por quais atores. Nesse sentido, não se trabalha com a noção de governança boa ou má, mas, sim, que o tipo de governança vai depender dos atores que se interessam pelo tema determinado, o qual se está tentando "regulamentar". Assim, é pertinente jogar luz nos atores envolvidos no processo, assim como no seu modus operandi.

Weiss (2000) trata das definições de governança consideradas por organizações internacionais com peso relevante no sistema internacional ${ }^{4}$. De acordo com o autor, o Banco Mundial define o termo em termos de como o poder é exercido e a forma como recursos sociais e econômicos são gerenciados. 0 Bird ainda identifica três aspectos da governança: 1) a forma do regime político; 2) o processo no qual a autoridade é exercida no gerenciamento dos recursos sociais e econômicos de um país para seu desenvolvimento; 3) a capacidade dos governos de desenhar, formular e implementar políticas e executar funções (WORLD BANK, 1994 apud WEISS, 2000). Já o Pnud (Programa das Nações Unidas para o Desenvolvimento) vê governança como o exercício de autoridade econômica, política e administrativa para gerenciar os assuntos de um país

\footnotetext{
${ }^{4}$ As OIGs são simultaneamente o objeto de estudo do trabalho bem como uma das fontes de literatura para tratar de conceitos do trabalho.
} 
em todos os níveis (PNUD, 1997 apud WEISS, 2000). Por fim, a OCDE (Organização para a Cooperação e o Desenvolvimento Econômico) afira que governança:

\begin{abstract}
denota o uso de autoridade política e o exercício de controle em uma sociedade em relação ao gerenciamento dos seus recursos para o desenvolvimento econômico e social. Essa definição abrangente cerca o papel das autoridades públicas em estabelecer o ambiente no qual os atores econômicos agem em determinar a distribuição de benefícios, assim como a natureza da relação entre aqueles que fazem as regras e aqueles a elas submetidos (OCDE, 1995, p. 14 apud WEISS, 2000, p. 797, tradução nossa).
\end{abstract}

O presente trabalho considera a noção de Rosenau (2000), que faz distinção entre governo e governança. Governo diz respeito a atividades apoiadas por uma autoridade formal, enquanto governança trata, em linhas gerais, de funções de um sistema humano sendo desempenhadas sem a existência de uma instituição para isso. São atividades apoiadas por objetivos compartilhados que podem ou não derivar de responsabilidades prescritas legal ou formalmente e que não necessariamente são amparadas por poder policial. Inclui governos, mas vai além, abarcando instituições informais com as quais as pessoas satisfazem suas necessidades e realizam seus desejos. Trata-se de um sistema de regras que só funciona se for aceito pela maioria e, fundamentalmente, tem a ver com um grupo ou sociedade buscando a satisfação de certas demandas. Rosenau considera que a governança está ligada a modelos de resolução de problemas, pois, para o autor, funções de governança são executadas por atores que não são governos.

Governança é um sistema de ordenação que depende de sentidos intersubjetivos, mas também de constituições e estatutos formalmente instituídos. Para dizê-lo mais claramente, a governança é um sistema de ordenação que só funciona se for aceito pela maioria (ou pelo menos pelos atores mais poderosos do seu universo), enquanto os governos podem funcionar mesmo em face de ampla oposição à sua política. Neste sentido, a governança é sempre eficaz, quando se trata das funções necessárias para a persistência sistêmica, ou então não é concebida para existir efetivamente (com efeito, não se fala em uma governança ineficaz, mas sim em anarquia ou caos) (ROSENAU, 2000, p. 16).

Portanto, governança seria a forma de os diversos atores da sociedade conviverem e satisfazerem suas necessidades, sendo que governos não dão conta de cumprir todas as demandas da vida social uma vez determinada a complexidade das demandas e situações que a sociedade enfrenta corriqueiramente.

Assim, é pertinente partir para o segundo passo proposto na reflexão, que diz respeito à noção de governança global. Nesse sentido, os elementos discutidos até aqui sofreriam com um fator complicador: a falta de autoridade constituída e legitimada no 
sistema internacional, ou seja, a falta de um governo ao qual os países devessem obediência. Em outras palavras, trata-se da anarquia do sistema internacional. Para Finkelstein, "governança global é governar sem autoridade soberana as relações que transcendem fronteiras nacionais. Governança global faz internacionalmente o que governos fazem domesticamente" (FINKELSTEIN, 1995, p. 369). Portanto, a governança, que já possui certa dificuldade de ser conseguida em termos domésticos, acaba tendo desafios a mais no que diz respeito ao sistema internacional. Mesmo assim, essa situação representa certo paradoxo, pois, apesar da dificuldade, acaba por ser um dos poucos instrumentos em nível internacional para que se obtenha alguma previsibilidade ou controle de ação a partir dos atores relevantes em tal nível.

Os conceitos de reciprocidade difusa, autoridade racional-legal e controle sobre conhecimento técnico auxiliam na perspectiva de se criar governança em um nível internacional. De acordo com Herz e Hoffman (2004), o conceito de reciprocidade difusa propõe que a expectativa de que todos ou quase todos os atores inseridos no sistema respeitarão as regras faz com que ocorra esse respeito, ou seja, ao se engajarem em determinadas práticas, os atores compartilham certa expectativa de continuidade da referida prática, aumentando a força das normas e do senso de obrigação dos atores (HERZ; HOFFMAN, 2004, p. 23-24; KEOHANE, 1986, p. 20-21 apud SCHLEICHER, 2006, p. 22). Já a legitimidade da autoridade racional-legal e o controle sobre conhecimento técnico e informativo são duas fontes de poder das OIGs. Os estudos de Haas (1992) sobre comunidades epistêmicas exemplificam como conhecimento técnico pode influenciar decisões políticas a partir de comunidades epistêmicas e outros grupos profissionais, como burocratas ou outros grupos baseados em conhecimento. Assim, a reciprocidade difusa, a autoridade racional-legal e o conhecimento técnico são três exemplos de criação de governança no sistema internacional.

Observa-se que as OIGs são fornecedoras de conceitos ou, ao menos, parâmetros conceituais para elementos de estudo em Ciência Política e Relações Internacionais, pois tratam da própria definição de governança. Ao mesmo tempo, tais organizações são responsáveis por determinar, em parte, o nível de governança em determinados temas da política internacional. Em outras palavras, as OIGs são stakeholders em diversos temas em que há nível de governança global e elas influem consideravelmente neste na criação de governança com diferentes mecanismos e prerrogativas. 


\section{Transnacionalismo}

Movimentos transnacionais não são novos. De acordo com Tarrow (2005), há uma história por trás da ênfase atual que se dá ao fenômeno. 0 autor retoma alguns movimentos históricos conhecidos, como a Reforma Protestante, o movimento antiescravista, a difusão do anarquismo e a expansão do nacionalismo, da imprensa e da linha férrea para determinar o que ele chama de difusão de movimentos transfronteiriços ${ }^{5}$. A mobilização internacional é um segundo mecanismo clássico para a ação coletiva transnacional e esses dois mecanismos configuram o que o autor chama de "modularidade", a adaptação das formas e concepções da ação coletiva.

Assim, o que seria novo nesse fenômeno, do ponto de vista do autor, é que, além de ser mais intenso e incluir maior número de atores e indivíduos, ele também está intimamente ligado ao movimento de globalização e relacionado às mudanças estruturais da política internacional. Nesse sentido, os recursos e as oportunidades para a ação coletiva acabam sendo também expandidos em possibilidades de se exercerem coalizões transnacionais (TARROW, 2005).

A interpretação possível dessa reflexão é que movimentos ativistas que possuem princípios e valores motivadores de sua formação e atuação, o que Keck e Sikkink (1998) chamam de transnational advocacy networks, tenham possibilidade de comunicação e organização sem precedentes, o que, por sua vez, pode articular muito melhor suas ações e, no limite, facilitar a obtenção de seus objetivos finais.

Para Barnett e Sikkink (2008, p. 63), a mudança de um mundo de relações internacionais para um de sociedade global é o resultado da rede crescente de atores estatais e não estatais envolvidos na produção e revisão de estruturas de governança global em diversas camadas. 0 ponto a ser enfatizado aqui é que o Estado não deixa simplesmente de ter relevância. Está-se diante de algo diferente. 0 Estado preserva a prerrogativa de fazer leis e de ser a autoridade em determinado território, ou seja, os movimentos transnacionais precisam, em certa medida, respeitar e seguir as normas estatais. Por outro lado, o grau de controle dos Estados sobre os diversos fluxos internacionais (pessoas, informação, bens, recursos, etc.) tem ficado cada vez mais comprometido. $\mathrm{O}$ Estado ainda é um ator extremamente relevante, mas precisa lidar com

\footnotetext{
${ }^{5}$ Em inglês, o autor utilizou o termo: diffusion of movements across borders (TARROW, 2005, p. 3).
} 
essas limitações crescentes. Os movimentos transnacionais possuem agenda determinada e possibilidade de articulação e organização avançadas no contexto atual. Não obstante, ainda precisam atuar e lidar com as regras feitas nos territórios onde atuam e que são determinadas pelos governos.

Os movimentos transnacionais também tratam de grupos tentando satisfazer demandas por caminhos que transcendem a autoridade estatal. Nesse sentido, a ligação entre governança e transnacionalismo é íntima. Grupos transnacionais buscam criar ou alterar a governança em determinada área ou tema. Assim, os movimentos transnacionais propriamente ditos também buscam alterar e impactar os sistemas domésticos para que as práticas nas supracitadas áreas estejam de acordo com o que tais movimentos preconizam.

Com efeito, estamos diante de dois elementos intimamente ligados: governança e transnacionalismo, e as estratégias de pesquisa podem levar em consideração o impacto doméstico que tais movimentos transnacionais criam em termos de governança. Em outras palavras, os movimentos transnacionais procuram criar governança em determinados temas (os temas aos quais os movimentos se dedicam, evidentemente), não podendo ignorar a atuação dos governos, mas transcendendo-a ao mesmo tempo. Assim, atuar no nível doméstico é fundamental para que tais movimentos consigam criar as estruturas de governança que eles buscam de acordo com sua agenda. É difícil determinar como se dá o início dessas estruturas, ou seja, como elas nascem. 0 sistema normativo do país onde o movimento está primeiramente instalado pode ser um ponto de partida, assim como o sistema normativo de um país que favoreça a atuação distinta do movimento. De qualquer maneira, o sistema doméstico é relevante para a atuação transnacional.

Há grande multiplicidade de movimentos transnacionais, o que significa que a atuação desses movimentos é extremamente diversa. Para compreender atores, movimentos e atuação, defende-se que a issue area em questão deve ser levada em conta.

Portanto, uma forma de estabelecer road maps para criar governança é algo importante a ser considerado por movimentos transnacionais. Nesse sentido, de acordo com as perspectivas desenvolvidas até aqui, o estabelecimento de governança passaria por três passos: 1) averiguar o tema (issue area) em questão. Os sistemas de governança e as práticas de diferentes atores são distintos quando se trata de direitos humanos, questões ambientais ou controle de armamento; 2) é fundamental identificar os major 
players da área temática em questão. Tais atores podem ser Estados, organizações internacionais, organizações não governamentais, etc. Claramente, nenhum ator deve ser ignorado, mas considera-se que os Estados serão, como argumenta Risse Kappen (1995), fundamentais para que se consiga criar práticas comuns nos diferentes atores; e 3) identificar o modelo de Estado(s) no qual (ou nos quais) se está querendo atuar no momento, uma vez que se entende que movimentos transnacionais objetivam atuar em múltiplos Estados. Mesmo assim, terão que flexibilizar a atuação para ser eficazes em sua agenda. Fica clara, assim, a interdependência entre os diversos atores das relações internacionais atuais. Esse aspecto reforça o papel das OIGs como atores relevantes e úteis tanto para Estados quanto para outros tipos de atores como canal de comunicação e validação de interesses.

\section{Lugar das organizações internacionais: uma síntese a partir da teoria}

A partir da junção das literaturas expostas até aqui, trata-se das OIGs como atores essenciais no modelo de se fazer política atualmente. Tais organizações teriam papel fundamental para influenciar e criar ideias que seriam, em alguma medida, adotadas ou que influenciassem decisões no sistema internacional. Exercendo esse papel, as OIGs teriam peso fundamental na criação de governança nos mais variados temas pertinentes em política e, não menos importante, seriam um canal de pressão e até de representação informal de outros atores transnacionais que estariam em busca de percorrer sua agenda.

Para Hurrel (2000, p. 3-5), as instituições internacionais possuem a ambição de internacionalizar valores que regulam quase todas as formas de relações interestatais e influenciar a maneira como as sociedades estão organizadas domesticamente. De acordo com o autor, a importância das instituições está, entre outras coisas, no fato de que elas ajudam a explicar como novas normas surgem e são difundidas no sistema internacional e como os interesses estatais mudam e evoluem. Assim, as instituições são os canais pelos quais as novas normas são transmitidas e aquelas que já foram alteradas são reforçadas. Além disso, é através de instituições interestatais que atores mais fracos podem absorver e aplicar normas. Portanto, o papel da Unesco, da OCDE e do Bird na formulação de diretrizes para o ensino superior é essencial para que as novas práticas e tendências sejam internalizadas pelos Estados.

Herz e Hoffman (2004, p. 73), analisando as organizações internacionais sob a perspectiva construtivista de Relações Internacionais, colocam como foco o processo de 
formação de identidade e interesses. As mudanças dessas duas variáveis e a relação entre elas são importantes para o construtivismo e, nesse sentido, ideias, valores, normas e crenças são variáveis explicativas fundamentais dos fenômenos do sistema internacional.

Segundo as autoras:

Para autores construtivistas, as instituições internacionais têm um papel fundamental, podendo mudar a definição de interesses e identidades dos Estados e de outros atores. Assim, as instituições não se limitam a constranger o comportamento dos atores ou a modificar a gama de opções disponíveis para os mesmos. Da mesma forma, essas instituições se transformam (HERZ; HOFFMAN, 2004, p. 75).

Os Estados, por sua vez, estão embutidos em um sistema social internacional e são atores relevantes desse sistema (os principais atores do sistema, segundo o neorrealismo, por exemplo). As instituições intergovernamentais são arenas de diálogo e interação entre os diferentes Estados. "As políticas externas e domésticas dos Estados podem ser influenciadas por normas internacionais, muitas vezes produzidas e difundidas a partir das organizações internacionais" (HERZ; HOFFMAN, 2004, p. 75-76).

Assim, as organizações internacionais possuem influência considerável na questão de formulações de práticas e ações no âmbito internacional e no âmbito doméstico dos Estados. Isso ocorre porque tais instituições têm papel importante, contemporaneamente, na questão das visões de mundo que ajudam a moldar as ações em política internacional e doméstica. Além disso, organizações como OCDE, Unesco e Bird, entre outras, são importantes canais de diálogo entre Estados e de acesso à informação de um Estado por outro. Dessa forma, é inegável a importância das organizações internacionais nas relações políticas internacionais e na implementação de políticas públicas domésticas dos Estados.

No entanto, é importante salientar a visão de Ricúpero (2011), na oportunidade da celebração de 60 anos da Organização das Nações Unidas, de que temos as instituições possíveis e não as mais adequadas. Basicamente, o autor afirma que, dados os apontamentos das limitações da organização, é necessário partir do ponto de que a própria ambição das conquistas institucionais não pode ser alta. Dito de outra forma, se fosse esperado que as OIGs consertassem os desequilíbrios e resolvessem todos ou grande parte dos conflitos existentes no sistema internacional, a premissa seria exagerada do ponto de vista da capacidade real de tais organizações. Assim, se estaria diante de uma instituição parecida com a falida Liga das Nações, que, resumidamente, propunha o que 
era ideal para o mundo do ponto de vista normativo, mas tais normas não tinham legitimidade e nenhum lastro na atuação dos atores preponderantes do sistema internacional da época.

A partir dos pontos aludidos da literatura teórica, esta seção do artigo tem o objetivo de listar cinco possíveis funções das organizações em questão. Reconhecendo todas as limitações e dificuldades de atuação das instituições, conjectura-se que elas são essenciais para:

1) servir de palco de encontro, diálogo e negociação para Estados. Podemos considerar que, no período pré-Primeira Guerra Mundial, os Estados organizavam congressos entre si e que isso seria possível nos dias de hoje. Não obstante, tal função é exercida mormente no âmbito das organizações interestatais, o que pode ser considerado uma evolução da capacidade de comunicação dos Estados. É bem pouco provável que haja estrutura de comunicação e negociação mais bem elaborada que seja fora das OIGs. Esse ponto, aliado aos outros adiante, torna essa capacidade consideravelmente mais robusta do que a dos Estados sozinhos;

2) produzir dados sobre os Estados e análises das mais diversas ordens. Os bancos de dados gerados pelas agências da ONU e pela OCDE, apenas para citar exemplos, são utilizados em larga escala para pesquisas, avaliações de políticas públicas e mesmo como instrumento de prestação de contas e transparência para formação de opinião pública sobre os mais diversos temas que são encarados de forma internacional e transnacional. Assim, as OIGs são, cada vez mais, uma referência como fontes de dados sobre Estados para comparação com outros Estados e com outros períodos de tempo em um mesmo Estado. A formação de conclusões com base em dados científicos também é importante para as OIGs. Segundo Haas (1992), as comunidades de cientistas trabalhando para essas organizações (comunidades epistêmicas) são fundamentais para a criação de consensos em diversas áreas do conhecimento, assim como para a divulgação desse conhecimento;

3) promover o embate entre posições dominantes e minoritárias. Esse é um ponto sensível das OIGs, pois trata de como o poder é exercido dentro dessas organizações. 0 ponto aqui é em que medida tais organizações reproduzem o jogo de poder criado no sistema internacional e dominado pelos Estados fortes. As principais críticas feitas às OIGs é que elas são uma imitação desse jogo de poder e que estão a 
serviço dos Estados fortes. Essa é uma afirmação de difícil refutação, pois a soberania dos Estados é inviolável e, uma vez que possuem capacidade material de agir em determinado contexto, irão agir à revelia das OIGs. Mesmo assim, há de se observar que a maioria dos Estados do sistema internacional é sensível às sanções que podem ser aplicadas por organizações interestatais. Mesmo Estados poderosos podem entrar em embate com as OIGs, ainda que sejam eles os maiores doadores e mantenedores. Nesse sentido, a observância de alguma alteração na conduta estatal é pouco provável, mas o embate é evidente e tem um efeito importante em termos de relações públicas: o jogo de poder fica claro para os diversos atores das relações internacionais, e as pressões de atores internacionais e domésticos podem ser traduzidas em certo desgaste para o Estado ou governo em questão. A saída dos Estados Unidos da Unesco na década de 1980 (HOCKING, 1985) é um exemplo de conflito entre Estado forte versus organização interestatal. Vale lembrar que não se espera que OIGs se sobreponham aos Estados, mas elas fazem um papel de fricção importante;

4) ser uma chance de representação de Estados com menor capacidade material. Estados emergentes e aqueles considerados fracos ou "pequenos" possuem limitações em relação a sua inserção no sistema internacional de tal forma que esses organismos representam um canal de representação e de formação de coalizão em torno de uma causa ou de reivindicações possíveis para satisfazerem suas demandas. Nesse sentido, OIGs podem ser uma das poucas formas de esses Estados terem voz no sistema internacional ou ao menos se juntarem para tal; e

5) ser canal difusor e de representação, dada a transnacionalidade dos diferentes temas das relações internacionais. No contexto de transnacionalidade e de sociedade global comentado no presente estudo, e com a própria noção de governança sendo cada vez mais um elemento que, em certa medida, atenua a anarquia do sistema internacional, os mais diversos temas são discutidos em âmbito internacional com a participação dos mais diversos atores. Com efeito, as organizações internacionais acabam por fazer parte desse conjunto de atores em torno da "transnacionalidade" e da criação de governança nos mais diversos temas a serem debatidos em âmbito internacional. No limite, as OIGs são parte do modelo no qual a política é exercida contemporaneamente, recebendo e exercendo pressões e demandas, difundindo políticas e ganhando experiência e expertise organizacional e relacional. 
As reflexões postas acima não esgotam o assunto ou mesmo as funções exercidas pelas organizações internacionais. Tampouco tais reflexões estão blindadas contra críticas ou relativização sobre a capacidade de cada organização de exercer essas funções no todo ou em suas partes, além de ser questionável o grau em que cada uma cumpre tais funções colocadas. Essas relativizações, contudo, não invalidam o exercício dos mais diversos papéis a partir das OIGs na política atual em nível internacional e transnacional.

\section{Considerações finais}

Este artigo buscou demonstrar, a partir de uma perspectiva teórica, como as organizações internacionais interestatais atuam em um contexto contemporâneo de política internacional. A referida contextualização partiu de reflexões teóricas acerca das relações internacionais (com letra minúscula, demonstrando as relações entre atores em âmbito internacional) e das Relações Internacionais (com letra maiúscula, em referência ao campo de estudo em questão). Desse modo, buscou-se elucidar a influência das ideias no campo da política juntamente com a discussão sobre governança global e transnacionalismo. A partir dessas três noções, a tentativa foi de mostrar como as OIGs atuam hodiernamente, tentando encontrar o espaço dessas instituições na política internacional. 0 ponto defendido é que o modelo de relações exercido hoje em dia é tal que essas organizações são indispensáveis fornecendo as cinco funções mencionadas no artigo, cabendo ressaltar que, mesmo sendo funções que podem ser encaradas como marginais ou que outros atores podem desempenhar, a linha de pensamento é que elas são necessárias (mesmo que marginais) e quem as desempenha são as OIGs (mesmo outros atores sendo capazes de fazê-lo).

Portanto, é pertinente o questionamento acerca de como cada organização desempenha cada função de acordo com o tema em questão. Como e quais ideias influenciam determinada tomada de decisão em torno de determinado tema? Qual é o grau de governança que uma questão possui em nível internacional? Quais são os atores que influenciam as gerações de consenso mínimo e de tomada de decisão em torno das discussões presentes nas mais diversas demandas sociais? Como os assuntos são "transnacionais" a ponto de mexer com interesses dos mais diversos e provocar atores a se envolverem nas arenas de discussão? Estudos específicos de casos em que as organizações interestatais estão envolvidas são necessários para que haja maior compreensão do papel e da influência desses atores no sistema internacional, assim como 
mais trabalhos teóricos que elucidem conjecturas a serem testadas e premissas que contemplem a complexidade do mundo também são imperativos.

\section{Bibliografia:}

BARNETT, Micheal; SIKKINK, Kathryn: From International Relations to Global Society. In REUS-SMIT, Christian; SNIDAL, Duncan: The Oxford Handbook of International Relations. Oxford University Press, 2008.

FINKELSTEIN, Lawrence: What is Global Governance? Global governance, vol 1, number 3 (sept. - dec. 1995), p. 367 - 372.

GOLDSTEIN, Judith e KEOHANE, Robert: Ideas and Foreign Policy: beliefs, institutions and political change.Cornell University Press, 1993.

KECK, Margareth E., SIKKINK, Kathryn: Activists Beyond Borders - Advocacy Networks in International Politics. Cornell University Press, 1998.

KEOHANE, Robert O.: Specific and Diffuse Reciprocity: Trade and Climate Change. IPES, November 12, 2010.

KEOHANE, Robert O.: Multilateralism: an agenda for research. International Journal. XLV, autumn, 1990.

KEOHANE, Robert 0.: The Promise of Institutionalist Theory. International Secuity. Vol 20. N 1 (summer 1995), p. 39-51.

HAAS, Peter M.: Epistemic Communities and International Policy Coordination. International Organization, Vol. 46, No. 1, Knowledge, Power, and International Policy Coordination (Winter, 1992), pp. 1-35

HALL, P. A.: The Political power of economic ideas: keynesianism across nations.Princeton: Princeton University Press, 1989.

HERZ, Mônica e HOFFMAN, Andrea: Organizações Internacionais: história e práticas.Rio de Janeiro. Elsevier. 2004.

HOCKING, Brian: Words and Deeds: why America left UNESCO. The World Today. Vol. 41, No. 4 (Apr., 1985), pp. 75-78. Published by: Royal Institute of International Affairs

HURREL, Andrew: Some reflections on the role of intermediate powers in international institutions. In: Paths to power: Foreign Policy strategies of intermediate states. Latin American Program. Woodrow Wilson International Center for Scholars, 2000.

JENSON, J. (1989): Paradigms and political discourse: protective legislation in France and 
United State before 1914. Canadian Journal of Political Science 22(2): 235-256.

RICÚPERO, Rubens: A Dificuldade de Construir Consenso Numa Era de Extremos. In RODRIGUES, Thiago, ROMÃO, Wagner de Melo: ONU no Século XXI: perspectivas. São Paulo, Desatino, 2011.

RISSE-KAPPEN, Thomas: Bringing Transnational Relations Back In. Cambridge - Print On. 1995.

SCHLEICHER, Raafael Tavares: Ciência, Política e Institucionalização na Cooperação Multilateral Contra o Aquecimento Global. Dissertação apresentada ao Programa de Mestrado em Relações Internacionais da Universidade de Brasília. Brasília, DF, 2006

TARROW, Sidney: The New Transnational Activism. Cambridge Studies in Contentious Politics. Cambridge University Press, 2005.

WEISS, Thomas G: Governance, Good Governance and Global Governance. Third World Quarterly, vol 21, n 5, p. 795-814, 2000. 